\title{
GC-MS analysis of steroids and triterpenoids occurring in leaves and tubers of Tamus edulis Lowe
}

\author{
Agata Rogowska $^{\mathrm{a}, 1, *}$, Michał Styczyński ${ }^{\mathrm{b}, 1}$, Cezary Pączkowski ${ }^{\mathrm{a}}$, Anna Szakiel ${ }^{\mathrm{a}}$, \\ Miguel Ângelo A. Pinheiro de Carvalho ${ }^{c}$ \\ ${ }^{a}$ Department of Plant Biochemistry, Faculty of Biology, University of Warsaw, ul. Miecznikowa 1, 02-096 Warszawa, Poland \\ ${ }^{\mathrm{b}}$ Department of Bacterial Genetics, Faculty of Biology, University of Warsaw, ul. Miecznikowa 1, 02-096 Warszawa, Poland

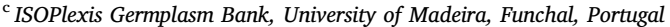

\section{A R T I C L E I N F O}

\section{Keywords:}

Tamus edulis

Dioscoreaceae

GC-MS

Steroids

Steroid sapogenins

Triterpenoids

\begin{abstract}
A B S T R A C T
Tamus edulis Lowe is an endemic perennial plant belonging to Dioscoreaceae family. The plant has long climbing stems, ovate leaves, flowers in spikes, fleshy red berries and long tuberous roots. Young shoots and tuberous roots of $T$. edulis were used traditionally for nourishment and as a herbal medicine. Leaves and roots analyzed in the present study were collected in the northwest of Madeira island. The GC-MS analysis allowed to detect several steroids in free forms in diethyl ether extracts; and diosgenin with its isomer, yamogenin, in hydrolyzates from methanolic extracts. The obtained results reveal that Tamus edulis has some features common with other Dioscorea species, e.g., the presence of steroidal saponins with diosgenin and yamogenin as aglycones, or the phytosterol composition with predominating sitosterol. However, some other traits, like the relatively high content of free steroids (more than $1 \mathrm{mg} / \mathrm{g} \mathrm{d.w.)} \mathrm{and} \mathrm{their} \mathrm{profile} \mathrm{rich} \mathrm{in} \mathrm{cholesterol} \mathrm{derivatives,} \mathrm{can} \mathrm{distinguish}$ Tamus edulis from other Dioscorea species studied previously for their steroid and triterpenoid profile.
\end{abstract}

\section{Introduction}

The Dioscoreaceae is a large plant family, that includes more than 600 species. Tamus edulis Lowe, a species belonging to this family, was described for the first time by Lowe (1831) as a species occurring in Madeira. This perennial plant was sporadically cultivated in remote areas of this island and widely known by common name „norça” (Pinheiro de Carvalho et al., 2016). Tubers and young shoots of T. edulis were used traditionally for nourishment and as a herbal medicine. The plant has long climbing stems, ovate leaves (Fig. 1), flowers in spikes, fleshy reddish berries when mature, and long brown tuberous roots with white-yellowish flesh. This species is considered as an endemic plant occurring naturally in Canary Islands and Madeira (Press and Short, 1994). Its endemicity is determined by its geographical and reproductive isolation. For a long time, Tamus has been considered as a monophyletic genus of flora of Madeira, holding T. edulis Lowe as a species with high genetic singularity (Press and Short, 1994; Borges et al., 2008). Tamus and Dioscorea genera were separated on the basis of fruit morphology: T. edulis forms a fleshy berry while Dioscorea forms dry capsule, however, recent biochemical and genetic data shows their close relation (Wilkin et al., 2005). Based on the analysis of herbarium voucher material, but in the absence of other studies, T. edulis has been currently clasiffied as one of numerous synonyms of Dioscorea communis (L.) Caddick and Wilkin (The Plant List, 2013). However, phylogenetic relationships between Dioscoreales used to be difficult to resolve (Chaïr et al., 2016). The confusion can be explained by high phenotypic variability of these species (Ferrer-Gallego and Boisset, 2016).

Plants belonging to Dioscoreaceae family are interesting from pharmaceutical point of view due to saponin content. Saponins possess cytotoxic, cytostatic, anti-tumoral and chemo-preventive activity (Lacaille-Dubois and Wagner, 2000). They also positively affect antioxidative enzymes (Son et al., 2007). González et al. (1970) isolated several steroidal sapogenins from $T$. edulis leaves and twigs collected in Canary Islands. Besides diosgenin, tamusgenin, eduligenin and lowegenin, some others, more rare aglycons, i.e. 7-ketotamusgenin, 7-ketodiosgenin, 25S-hydroxytamusgenin and afurigenin were also identified (González et al., 1970, 1971). However, the whole profile of steroids and triterpenoids, particularly occurring in this plant in a free form, has not been investigated yet. Thus, the main aim of the present study was the qualitative and quantitative GC-MS analysis of non-

\footnotetext{
* Corresponding author.

E-mail addresses: a.rogowska@biol.uw.edu.pl (A. Rogowska), mstyczynski@biol.uw.edu.pl (M. Styczyński), myhacp@biol.uw.edu.pl (C. Pączkowski), szakal@biol.uw.edu.pl (A. Szakiel), miguel.carvalho@staff.uma.pt (M.Â.A. Pinheiro de Carvalho).

${ }^{1}$ These authors contributed equally to this paper.
} 


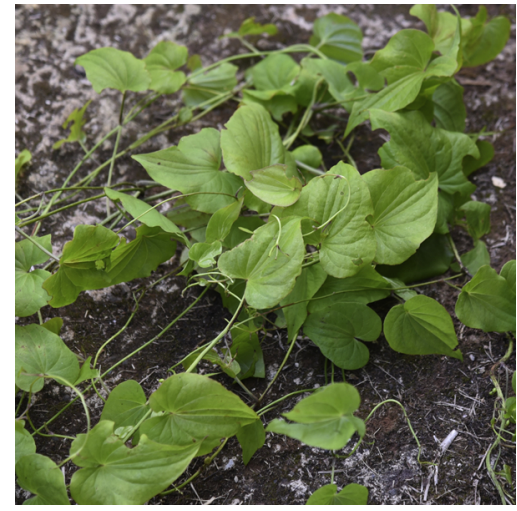

Fig. 1. Tamus edulis Lowe.

glycosylated steroids and triterpenoids occurring in leaves and tubers of Tamus edulis from Madeira island. Moreover, the determination of the main sapogenins occurring in the leaves and tubers were performed. Detailed biochemical investigation of $T$. edulis Lowe can shed more light on its taxonomy and help to solve some nomenclatural questions.

\section{Results and discussion}

\subsection{Identification of steroids and triterpenoids occurring in leaves and} tubers of T. edulis

GC-MS analysis of the fractions containing steroids and neutral triterpenoids obtained from diethyl ether extracts of leaves and tubers of analyzed plant revealed the presence of numerous steroids. Namely, several typical sterols (numbered according to their retention times), i.e. dominating sitosterol (6), accompanied by its saturated derivative, sitostanol (7), followed by cholesterol (1), campesterol (2), stigmasterol (5) and isofucosterol (8) were identified. Additionally, several steroids, i.e. cycloartanol (9), 24-methylenecycloartanol (14), cycloartenol (11), two derivatives of cholest-7-en-3-ol (4-methyl- and 2,2-dimethylcholest-7-en-3-ol, 3 and 4), and two ketones, tremulone (stigmasta-3,5dien-7-one, 13) and sitostenone (15) were found in both leaf and tuber extracts. In turn, small peaks of pentacyclic triterpenoids, i.e. $\alpha$ - and $\beta$ amyrins (10 and 12), were detected exclusively in tuber extract.
As in the previous report on leaf extracts of other twelve Dioscorea spp. (Szakiel et al., 2017), no free form of diosgenin, the aglycone of the saponin dioscin typical for numerous Dioscoreaceae species, was detected in T. edulis samples analyzed in this study.

The prevailing compounds identified in the fractions of aglycones were diosgenin, (25R)-spirost-5-en-3-ol (16), and its isomer, yamogenin, (25S)-spirost-5-en-3-ol (17). They were found in both analyzed extracts, pointing to the occurrence of significant amounts of steroid saponins not only in the tubers, what is typical for Dioscoraceae plants, but also in the leaves of $T$. edulis. The occurrence of several structurally related steroidal saponins in leaves and twigs of T. edulis was reported before (González et al., 1970, 1971), but only small amounts of unidentified sapogenins other than diosgenin and yamogenin were detected in the present study. From several steroids detected in free forms in diethyl ether extracts, in hydrolyzed methanolic extracts only small peaks of cholesterol and sitosterol were found, suggesting that these two sterols were present in plant also in the form of glycosides.

Free steroids can be unequivocally identified by their fairly consistent mass spectra, in which a molecular ion is usually easily observed, and it can have significant intensity (e.g., ion 386 of cholesterol or ion 414 in sitosterol). Another typical ion is $[\mathrm{M}-18]^{+}$, which is produced after the loss of $3 \beta$-hydroxy group as water. Further fragmentation by a retro-Diels-Alder reaction leads to other diagnostic ions. MS recognition of various types of triterpenoid isomers like $\alpha$-amyrin and $\beta$-amyrin, or diosgenin and yamogenin, can be made by comparison of intensity of some characteristic ion fragments. Fragmentation of both amyrins gives the base peak at $m / z 218$ (due to retro-Diels-Alder rearangement at C12) and accompying ions at $\mathrm{m} / \mathrm{z} 189$ and 203. However, the intensity of accompying ions 189 and 203 is different, i.e. 189 is markedly higher than 203 in $\alpha$-amyrin, and inversely, 203 is higher than 189 in $\beta$-amyrin. Fragmentation of diosgenin and yamogenin gives one of the base ions at $m / z 282$, and the characteristic accompying ion at $m / z 139$. The intensity of these two ions is significantly different in both isomers, i.e. 139 is notably higher than 282 in diosgenin, whereas in yamogenin the inverse ratio of these two peaks can be observed.

The calculated linear retention indices (Table 1) of analysed compounds were comparable to those reported in the literature (Isidorov and Szczepaniak, 2009).

The structures of identified compounds are presented in Figs. 2 and 3.

Table 1

Retention times and content of steroids and triterpenoids identified in Tamus edulis leaves and tubers.

\begin{tabular}{|c|c|c|c|c|}
\hline Compound & Retention time [min] & LRI $^{*}$ & Tuber & Leaf \\
\hline & & & \multicolumn{2}{|c|}{ ( $\mu$ g/g d.w. \pm S.D. $)$} \\
\hline Cholesterol (1) & 31.52 & 3128 & $59.38 \pm 7.22$ & $46.25 \pm 5.70$ \\
\hline Campesterol (2) & 34.22 & 3234 & $69.97 \pm 8.01$ & $41.93 \pm 4.69$ \\
\hline 4-methyl-cholest-7-en-3-ol (3) & 34.52 & 3245 & $11.06 \pm 1.90$ & $60.13 \pm 5.81$ \\
\hline 2,2-dimethyl-cholest-7-en-3-ol (4) & 34.86 & 3257 & $8.64 \pm 1,16$ & $17.15 \pm 2.03$ \\
\hline Stigmasterol (5) & 35.12 & 3266 & $156.30 \pm 22.05$ & $91.50 \pm 8.92$ \\
\hline Sitosterol (6) & 36.99 & 3325 & $453.79 \pm 56.23$ & $494.08 \pm 61.38$ \\
\hline Sitostanol (7) & 37.23 & 3332 & $24.36 \pm 2.88$ & $25.72 \pm 2.92$ \\
\hline Isofucosterol (8) & 37.48 & 3339 & $43.91 \pm 4.75$ & $70.01 \pm 6.95$ \\
\hline Cycloartanol (9) & 37.87 & 3350 & $36.58 \pm 4.02$ & $50.16 \pm 4.88$ \\
\hline$\beta$-Amyrin (in tubers) $(\mathbf{1 0})$ & 38.01 & 3354 & $16.42 \pm 2.14$ & - \\
\hline Cycloartanol (11) & 39.34 & 3391 & $31.64 \pm 3.02$ & $30.54 \pm 2.96$ \\
\hline$\alpha$-Amyrin (in tubers) (12) & 39.62 & 3399 & $14.92 \pm 1.66$ & - \\
\hline Stigmasta-3,5-dien-7-one (13) & 40.08 & 3410 & $56.81 \pm 6.37$ & $95.12 \pm 8.04$ \\
\hline 24-methylenecycloartanol (14) & 41.52 & 3442 & $27.19 \pm 3.45$ & $25.64 \pm 2.80$ \\
\hline Sitostenone (15) & 42.40 & 3462 & $24.44 \pm 2.90$ & $9.02 \pm 1.62$ \\
\hline Sum of free triterpenoids: & & & 1035.41 & 1057.25 \\
\hline Diosgenin (16) & 35.80 & 3289 & $1600.56 \pm 182.64$ & $562.47 \pm 60.15$ \\
\hline Yamogenin (17) & 37.30 & 3334 & $1264.28 \pm 133.02$ & $447.07 \pm 51.11$ \\
\hline Sum of aglycones: & & & 2864.84 & 1009.54 \\
\hline
\end{tabular}

\footnotetext{
* Linear retention index
} 
<smiles>CC(C)CCCC(C)C(C)CCC1C(CCCC(C)C)CCC2C3=CCC4C(C)C(O)CCC4C3(C)CCC21</smiles>

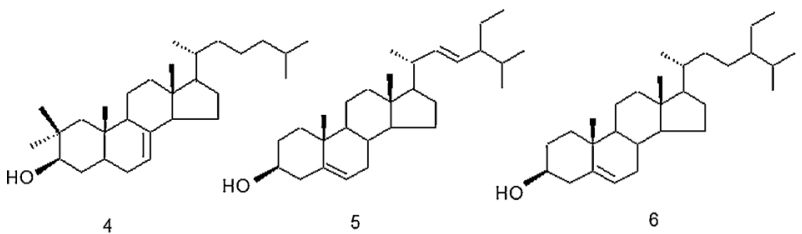

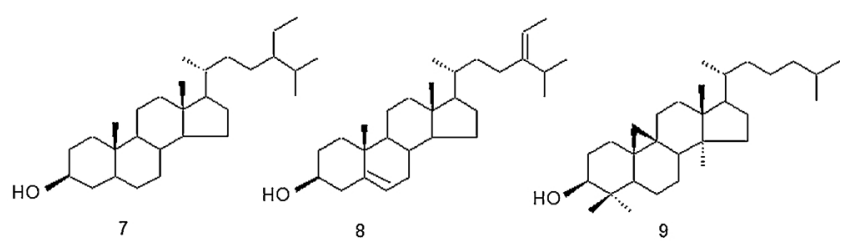

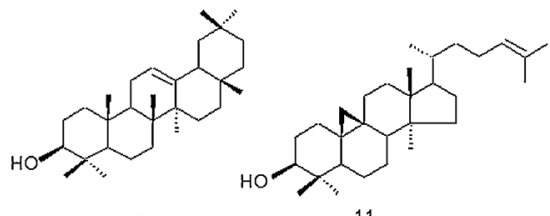

11<smiles>CC1CCC(C)C2C1CCC1C2CCC2(C)C3CCC(O)C(C)(C)C3CCC12C</smiles><smiles>C=C(CCC1CCC2C3CCC4C(C)CCC(C)C4(C)C3CCC12CCC(C)C(C)C)C(C)CCC(C)CC</smiles>

14

Fig. 2. Chemical structures of free steroids and triterpenoids identified in $T$. edulis leaves and tubers.

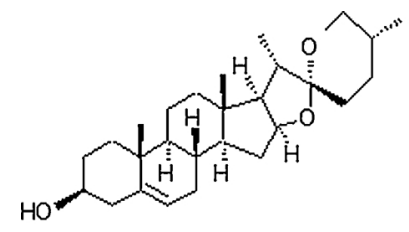

16

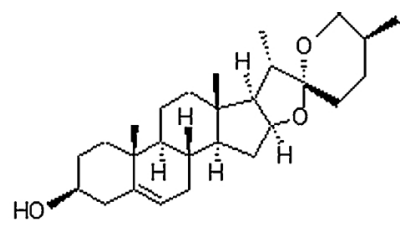

Fig. 3. Chemical structures of steroidal sapogenins identified in T. edulis leaves and tubers.

\subsection{Quantification of steroids and triterpenoids occurring in leaves and tubers of T. edulis}

The results of quantitative determination of identified compounds are presented in Table 1. The total contents of free steroids and triterpenoids in leaf and tuber extracts were similar and added up to approx. $1 \mathrm{mg} / \mathrm{g}$ of dry weight. This amount is relatively high as compared to the contents previously determined in other Dioscorea species, in which the amount of free steroids and triterpenoids ranged from 0.5 to $0.8 \mathrm{mg} / \mathrm{g}$ (with one exception of Dioscorea caucasica leaves containing very high level of pentacyclic triterpenoids). Sitosterol was the most abundant compound, constituting 44 and $47 \%$ of total contents in tubers and leaves, respectively. The second abundant phytosterol was stigmasterol. Tuber extracts additionally contained very small amount (approx. $31 \mu \mathrm{g} / \mathrm{g}$ ) of pentacyclic triterpenoids.

The report on sterol profile in Tamus communis (current synonym:

Dioscorea communis) collected in Italy (Capasso et al., 1983) revealed that sitosterol, stigmasterol and campesterol were the most abundant in roots and leaves of this plant, with the relative ratio of approx. 2:1:1, similar in both organs (although different from the ratio of these compounds in berries). In the present study on $T$. edulis the ratios of these phytosterols were approx. 7:2:1 in tubers, and 12:2:1 in leaves, thus significantly different than in $D$. communis.

Analyzed hydrolyzates of methanolic extracts of T. edulis tubers and leaves contained high amounts of sapogenins, i.e. diosgenin and yamogenin, and their total content accounted for almost $3 \mathrm{mg} / \mathrm{g}$ d.w. in tubers and $1 \mathrm{mg} / \mathrm{g}$ d.w. in leaves. Diosgenin was the prevailing isomer, constituting $56 \%$ of the sum of sapogenins both in tubers and leaves. Although the amount of aglycones in T. edulis leaves was found to be almost 3-times lower than in tubers, the leaves can still be considered as an important source of steroidal saponins.

Diosgenin is the dominant aglycone of the majority of saponins found in plants of various Dioscorea species, including $D$. communis, in which several glycosides having diosgenin as aglycone (i.e. dioscin and gracillin, as well as methylprotodioscin, methylprotogracillin and methylprotoneodioscin) were identified (Aquino et al., 1986, 1991). However, the saponin profile of $T$. edulis reported previously by González et al. $(1970,1971)$ seems to support a supposition of a distinction of these two species.

The obtained results reveal that Tamus edulis has some features typical for all Dioscorea species, e.g., the presence of steroidal saponins with diosgenin and yamogenin as aglycones, the absence of free sapogenins, the phytosterol composition with predominating sitosterol. However, some other traits, like the relatively high content of free steroids (more than $1 \mathrm{mg} / \mathrm{g}$ d.w.) and their profile rich in cholesterol derivatives, can distinguish Tamus edulis from other Dioscorea species studied to date for their steroid and triterpenoid profile (Szakiel et al., 2017).

\section{Experimental}

\subsection{Plant material}

Leaves and tuberous roots of T. edulis used in this study were collected in September 2017, in the northwest part of Madeira Island $\left(32^{\circ} 51.3043^{\prime} \mathrm{N}, 17^{\circ} 10.4078^{\prime} \mathrm{W}\right)$. After collection, samples were dried and homogenized.

\subsection{Extraction and fractionation}

Dried tubers and leaves were homogenized to a fine powder in a grinding mortar, then extracted first with diethyl ether, and afterwards with methanol (each extraction lasting $8 \mathrm{~h}$ ) in a Soxhlet apparatus. The obtained extracts were evaporated to dryness at $40^{\circ} \mathrm{C}$ under reduced pressure. The diethyl ether extracts were fractionated by preparative TLC in the solvent system $\mathrm{CHCl}_{3} / \mathrm{MeOH}(97: 3, \mathrm{v} / \mathrm{v})$. The methanolic extracts were subjected to acid hydrolysis by boiling under reflux with $10 \%$ hydrochloric acid in methanol for $120 \mathrm{~min}$ and the aglycones liberated from glycosides were extracted from hydrolyzates with diethyl ether. The fractions of diethyl ether extracts containing free triterpenoids, and the aglycones from hydrolyzed saponins obtained from methanolic extracts, were analyzed directly by GC-MS.

\subsection{Identification and quantification}

The analyses were performed using an Agilent Technologies $7890 \mathrm{~A}$ gas chromatograph (Perlan Technologies, Warsaw, Poland) coupled to 5975C mass spectrometric detector and equipped with a flame ionization detector, FID. All of the samples were dissolved in diethyl ether/ methanol $(5: 1, v / v)$ and a volume of $1-4 \mu \mathrm{l}$ was applied by split injection 1:10. The GC separation was made on a HP-5MS UI column of $30 \mathrm{~m} \times 0.25 \mathrm{~mm}$ i.d., film thickness $0.25 \mu \mathrm{m}$ (Agilent Technologies) in 
the temperature programme: initial temperature of $160^{\circ} \mathrm{C}$ held for $2 \mathrm{~min}$, then increased to $280^{\circ} \mathrm{C}$ at $5{ }^{\circ} \mathrm{C} / 1 \mathrm{~min}$ and the final temperature of $280^{\circ} \mathrm{C}$ held for further $44 \mathrm{~min}$ with constant helium flow rate of $1 \mathrm{ml}$ $\mathrm{min}^{-1}$. For GC-MS/FID detection the following parameters were employed: inlet and a flame ionization detector (FID) temp. $290^{\circ} \mathrm{C}$, MS transfer line temp. $275^{\circ} \mathrm{C}$, quadrupole temp. $150{ }^{\circ} \mathrm{C}$, ion source temp.

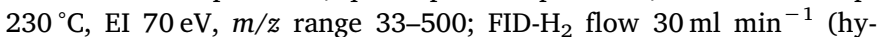

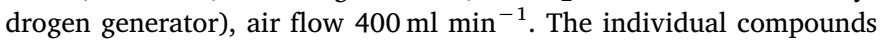
were identified by comparing their mass spectra with library data from Wiley 9th ED. \& NIST 2008 Lib. SW (Version 2010) or data from the literature, and by comparison of their retention times and corresponding mass spectra with those of authentic standards: $\alpha$-amyrin (Roth, Karlsruhe, Germany); $\beta$-amyrin, campesterol, cholesterol, diosgenin, sitosterol, and stigmasterol (Sigma-Aldrich, Steinheim, Germany). The standards were of GC grade $>98.5 \%$. Retention indices were calculated with the use of equation LRI $=100\left(n+t-t_{n} / t_{n+1}-t_{n}\right)$, where $\mathrm{t}=$ retention time of component, $\mathrm{n}=$ carbon number of preceding $n$-alkane, $\mathrm{n}+1=$ carbon number of subsequent $\mathrm{n}$-alkane from homologous series of $n$-alkanes. The identified compounds were quantified using external standard method based on calibration curves determined for typical representatives of each triterpenoid group analyzed in this study: $\alpha$-amyrin for monohydroxyalcohols, and stigmasterol for steroids. Calibration curves were drawn between the peaks areas versus the concentration of $\alpha$-amyrin (linear regression equation $\mathrm{y}=45800 \mathrm{x}-300)$ and stigmasterol $(\mathrm{y}=35900 \mathrm{x}-550)$ in the range of $0.002-2.0 \mathrm{mg} / \mathrm{ml}$. The correlation coefficient $\left(\mathrm{r}^{2}\right)$ values of $\alpha$-amyrin was 0.999 and for stigmasterol 0.998. RSD values of peak areas were less than 4\%. The LOD (Limit of Detection) was determined by analysis of samples with decreasing level of concentration of analyte, value for $\alpha$-amyrin was $0.8 \mu \mathrm{g} / \mathrm{ml}$, for stigmasterol $1.0 \mu \mathrm{g} / \mathrm{ml}$. A $2.5 \mu \mathrm{g} / \mathrm{ml}$ and $3.2 \mu \mathrm{g} / \mathrm{ml}$ limit of quantification (LOQ) was attained for $\alpha$-amyrin and stigmasterol, respectively.

\subsection{Statistical analysis of data}

All data are presented as the means \pm standard deviation of three independent samples analyzed in triplicate.

\section{Declaration of interest}

None.

\section{Acknowledgements}

The study was performed owing to the traineeship of Agata Rogowska and Michał Styczyński in University of Madeira (1.0830.09.2017) funded by the Programme of Professional Internships for Students POWR.03.01.00-00-S275/15.

Analyses were carried out with the use of CePT infrastructure financed by the European Union-the European Regional Development Fund (Agreement POIG.02.02.00-14-024/08-00).

\section{Appendix A. Supplementary data}

Supplementary material related to this article can be found, in the online version, at doi:https://doi.org/10.1016/j.phytol.2019.01.012.

\section{References}

Aquino, R., Behar, I., De Simone, F., D’Agostino, M., Pizza, C., 1986. Furostanol oligosides from Tamus communis. J. Nat. Prod. 49 (6), 1096-1101. https://doi.org/10.1021/ np50048a021.

Aquino, R., Conti, C., De Simone, F., Orsi, N., Pizza, C., Stein, M.L., 1991. Antiviral activity of constituents of Tamus communis. J. Chemotherapy 3, 305-309. https://doi. org/10.1080/1120009X.1991.11739110.

Borges, P.A.V., Abreu, C., Aguiar, A.M.F., Carvalho, P., Jardim, R., Melo, I., Oliveira, P., Sérgio, C., Serrano, A.R.M., Vieira, P., 2008. A list of the terrestrial fungi, flora and fauna of Madeira and Selvagens archipelagos. Direcção Regional do Ambiente da Madeira and Universidade dos Açres, Funchal and Angra do Heroísmo. pp. 440.

Capasso, F., De Simone, F., Senatore, F., 1983. Sterol constituents of Tamus communis L. J. Ethnopharmacol. 8, 327-329. https://doi.org/10.1016/0378-8741(83)90070-3.

Chaïr, H., Sardos, J., Supply, A., Mournet, P., Malapa, R., Lebot, V., 2016. Plastid phylogenetics of Oceania yams (Dioscorea spp., Dioscoreaceae) reveals natural interspecific hybridization of the greater yam (D. alata). Bot. J. Linn. Soc. 180, 319-333. https://doi.org/10.1111/boj.12374.

Ferrer-Gallego, P.P., Boisset, F., 2016. Typification of Dioscorea communis and its synonym Tamus communis var. Subtriloba (Dioscoreaceae). Phytotaxa 260, 258-266. https://doi.org/10.11646/phytotaxa.260.3.5.

González, A.G., Freire, R., Salazar, J.A., Suárez, E., 1970. Eduligenin and lowegenin, two new steroidal sapogenins from Tamus edulis. Phytochemistry 9, 1641-1646. https:// doi.org/10.1016/S0031-9422(00)85289-9.

González, A.G., Freire, R., Salazar, J.A., Suárez, E., 1971. 7-Ketotamusgenin, 7-ketodiosgenin, 25S-hydroxytamusgenin and afurigenin, four new steroidal sapogenins from Tamus edulis. Phytochemistry 10, 1339-1346. https://doi.org/10.1016/S00319422(00)84338-1.

Isidorov, V.A., Szczepaniak, L., 2009. Gas chromatographic retention indices of biologically and environmentally important organic compounds on capillary columns with low-polar stationary phases. J. Chromatogr. A 1216, 8998-9007. https://doi.org/10. 1016/j.chroma.2009.10.079.

Lacaille-Dubois, M.A., Wagner, H., 2000. Bioactive Saponins from Plants: an Update, vol. 21. Stud. Nat. Prod. Chem. Elsevier, pp. 633-687. https://doi.org/10.1016/S15725995(00)80015-0.

Lowe, Th.R., 1831. Tamus edulis. Trans. Cambr. Philos. Soc. 4, 12-13.

Pinheiro de Carvalho, M.Â.A., Bebeli, P.J., da Silva, A.M.B., Bettencourt, E., Slaski, J.J. Dias, S., 2016. Agrobiodiversity: The Importance of Inventories in the Assessment of Crop Diversity and Its Time and Spatial Changes In Genetic Diversity and Erosion in Plants. Springer. Cham., pp. 307-335. https://doi.org/10.1007/978-3-319-259543 .9.

Press, J.R., Short, M.J., 1994. Flora of Madeira. The Natural History Museum. H.M.S.O, London.

Son, I.S., Kim, J.H., Sohn, H.Y., Son, K.H., Kim, J.S., Kwon, C.S., 2007. Antioxidative and hypolipidemic effects of diosgenin, a steroidal saponin of yam (Dioscorea spp.), on high-cholesterol fed rats. Biosci. Biotechnol. Biochem. 71, 3063-3071. https://doi. org $/ 10.1271 /$ bbb.70472.

Szakiel, A., Grabarczyk, M., Pączkowski, C., Mieczkowski, A., 2017. Comparison of the profiles of non-glycosylated triterpenoids from leaves of plants of selected species of genus Dioscorea. Phytochem. Lett. 20, 350-355. https://doi.org/10.1016/j.phytol. 2016.11.013.

The Plant List, 2013. Version 1.1. Published on the Internet. (Accessed 8 October 2018). http://www.theplantlist.org/tpl1.1/record/kew-267912.

Wilkin, P., Schols, P., Chase, M.W., Chayamarit, K., Furness, C.A., Huysmans, S., Thapyai, C., 2005. A plastid gene phylogeny of the yam genus, Dioscorea: roots, fruits and Madagascar. Syst. Bot. 30, 736-749. https://doi.org/10.1600/ 036364405775097879 . 